(c) American Dairy Science Association, 2004.

\title{
Prevalence of Multidrug Resistant Staphylococcus aureus in Milk from Large- and Small-Scale Producers in Kenya
}

\author{
A. Shitandi ${ }^{1}$ and $\AA$. Sternesjö ${ }^{2}$ \\ ${ }^{1}$ Department of Food Science, Egerton University, Njoro, Kenya \\ ${ }^{2}$ Department of Food Science, Swedish University of Agricultural Sciences, \\ S-750 07 Uppsala, Sweden
}

\section{ABSTRACT}

This study evaluated the prevalence of multidrug resistant Staphylococcus aureus in Kenyan milk and investigated any differences in antimicrobial resistance between large- $(>200 \mathrm{~L} / \mathrm{d})$ and small- $(<50 \mathrm{~L} / \mathrm{d})$ scale producers. Susceptibility profiles for penicillin G, tetracycline, erythromycin, trimethoprim/sulfamethazine, and chloramphenicol were determined for Staph. aureus $(\mathrm{n}=402)$ isolated from cows with subclinical mastitis. There was a significant difference in the overall mean resistance profile between large- $(7.1 \%)$ and small-scale farm (14.7\%) isolates. The overall prevalence of multidrug resistance ( $\geq 2$ antibiotics) differed significantly between isolates from small farms (34.3\%) and those from large farms (18.0\%). Additionally, the producers were interviewed about their usage of antimicrobial drugs and their attitudes toward education in related fields. There was an evident difference between the producer types in their documentation of the use of antimicrobial drugs. Small-scale farms were less inclined to documentation, and treatment records were available from $22 \%$ of small-scale farms, compared with $73 \%$ of large-scale farms. Farmers expressed a need for more information in 5 areas, ranking preventive management highest (34.0\%); followed by affordable tests to control residues in milk (22.8\%); preparation of antimicrobial drugs (20.0\%); public health concerns (11.2\%); disposal of surplus antimicrobial drugs (7.8\%); and antimicrobial drug residue persistence in milk $(4.2 \%)$. It was concluded that herd size might be an indirect risk factor in the development of antimicrobial resistance in Staph. aureus within the region.

(Key words: antimicrobial drug resistance, Staphylococcus aureus, milk, Kenya)

Abbreviation key: CMT = California mastitis test.

Received February 9, 2004.

Accepted August 18, 2004.

Corresponding author: A. Sternesjö; e-mail: ase.sternesjo@ lmv.slu.se.

\section{INTRODUCTION}

In Kenya the overall consumption of antimicrobial drugs in animal production is estimated at $14,594 \mathrm{~kg} /$ yr; tetracyclines, $\beta$-lactams, trimethoprim/sulfa, nitrofurans, aminoglycosides, and quinolones being the most commonly used drugs (Mitema et al., 2001). As in most countries, it is not possible to specify the amount of different drugs used in specific animal production types. The majority of the antimicrobial drugs, however, are used to treat mastitis in dairy cattle, Staphylococcus aureus being the main target (Odongo and Ambani, 1989). Concern has been raised regarding the indiscriminate or unnecessary use of veterinary drugs, particularly when used in all cows without first determining their infection status. In Kenya, many of the large dairy producers adhere to recommended management regimens and may have documented records on antimicrobial drug usage. The large-scale producers, however, only contribute $30 \%$ of the produced milk in the country, whereas the remaining $70 \%$ comes from small dairy farms (Omore et al., 1999). Milk from small dairy farms is often consumed locally, being collected daily and sold unrefrigerated by local traders, the so-called hawkers. The small-scale producers, with fewer resources and lacking relevant knowledge, may not follow recommended treatment regimens when using antibiotics, as manifested in the higher prevalence of antimicrobial drug residues in their milk (Shitandi and Sternesjö, 2003).

It is well known that the usage of antimicrobial agents correlates with the emergence and maintenance of drug resistance in the microbial flora of animals. Although there is evidence suggesting that development of antibiotic-resistant human microflora in hospitals is mainly caused by the use of antimicrobial agents by the medical profession (Wiedemann, 1993), the impact of the use of antibiotics in agriculture on resistance development in humans remains to be determined.

The objective of this study was to compare antibiotic susceptibilities of Staph. aureus isolates from the 2 dairy producer categories in Kenya. It was hypothesized that if there were any differences in adherence to recom- 
mended regimens of the use of antimicrobial drugs, it would be manifested in the resistance profile of Staph. aureus isolates from the 2 producer categories.

\section{MATERIALS AND METHODS}

\section{Selection of Dairy Farms and Sampling of Milk}

The study was undertaken in the Nakuru district of the Rift Valley, Kenya, and the animals consisted of crosses of Friesian and domestic cattle. The farms (approximately 500 herds) were selected on their willingness to participate and were visited for milk sampling during 2001 and 2002 . The majority of animals were 3 lactations old or less and in the first 3 mo of the current lactation. The herds that were visited were divided into 2 categories, small-scale ( $<50 \mathrm{~L} /$ herd per d) and largescale producers ( $>200 \mathrm{~L} /$ herd per d), although there was no distinct cutoff between the 2 . On average, the small farms had 5 lactating animals, and the large herds had an average size of 40 lactating animals.

During the farm visits, lactating cows were randomly selected for collection of milk samples and initially screened for subclinical mastitis using the California mastitis test (CMT). Samples from cows with clinical mastitis were not included in this study. The CMT (DeLaval, Wroclaw, Poland) was carried out as described by Schalm and Noorlander (1957). The reaction was visually scored as 1 to 5 according to the Scandinavian recommendations (Klastrup and Schmidt, 1974) where a score $\geq 2$ was regarded as positive. Cows with a positive CMT result had quarter-milk samples collected according to IDF Standard 50 B (1985). Samples were immediately cooled and transported to the microbiology laboratory at Egerton University for identification of Staph. aureus. During sampling, the milk producers were interviewed regarding herd management in relation to mastitis and antimicrobial drug therapy and asked whether there were specific areas where they felt a need for education.

\section{Bacteriological Examinations}

Isolation and identification of Staph. aureus were performed according to the National Mastitis Council recommendations on examination of quarter-milk samples (1992). Briefly, immediately after delivery, the milk samples were inoculated on blood agar plates (Difco, Detroit, MI), which were divided into 4 sections. A 10 $\mu \mathrm{L}$ loop was used to streak the milk sample, and 6 to 8 lines were made in one agar section. Samples were incubated for 24 to $72 \mathrm{~h}$ at $37^{\circ} \mathrm{C}$ and examined for bacterial growth. Pure cultures were further examined for morphological, staining, and cultural characteristics, and for biochemical reactions according to stan- dard keys. Staphylococci were studied in particular for hemolysis and coagulase production. Coagulase testing was performed according to a tube method using oxalated rabbit plasma in a 1:10 dilution in a nutrient broth (Arbeit, 1988). Only typical colonies identified as Staph. aureus were stored in cryogenic vials containing $1 \mathrm{~mL}$ of trypticase soy broth containing $15 \%$ glycerin at $-80^{\circ} \mathrm{C}$.

\section{Antibiotic Susceptibility Testing}

From the Staph. aureus isolates, 201 were selected from each of the 2 producer categories, each isolate representing a single strain from a single herd. Before antibiotic susceptibility testing (NCCLS, 2002), the isolates were revived by subculturing on blood agar base (Difco) at $35^{\circ} \mathrm{C}$ for $24 \mathrm{~h}$. The isolates were tested for their susceptibility to 5 different antimicrobial drugs: penicillin G, tetracycline, erythromycin, trimethoprim/ sulfamethazine, and chloramphenicol. The antibiotic disks (Oxoid, Amsterdam, The Netherlands) were gently pressed to ensure contact with the inoculated Mueller-Hinton agar surface, and the plates were incubated at $35^{\circ} \mathrm{C}$. The plates were examined after $18 \mathrm{~h}$ and the zones of inhibition were measured to the nearest millimeter. The interpretive breakpoints for resistance were determined according to the standard table provided by the manufacturer of the antibiotic disks, and the isolates were reported as susceptible, intermediate, or resistant. For quality control, Staph. aureus ATCC 25923 was used as control strain. It should be pointed out that the interpretive breakpoints used were originally developed for human infections.

Analysis of susceptibility testing was by category agreement, where the zone diameters were divided into different categories (susceptible, intermediate, and resistant). Statistical significance of differences in resistance was evaluated using Minitab software (version 2000). The $\chi^{2}$-test with Yates correction was performed on the cross-tabulated categories resistant/susceptible, after combining intermediate and resistant isolates into one category (resistant). A $P$ value of $<0.05$ was considered statistically significant.

\section{Semi-Structured Interview}

A pretested semiquantitative questionnaire was used to determine descriptive characteristics of both smalland large-scale producers, interviews being carried out as adapted from Veldhuizen et al. (1997). The facilitator prepared a checklist of important indices and exercises (ranking) to be covered. This allowed the interview to be flexible and permitted the respondents to express their thoughts in their own words and within their own 
Table 1. Susceptibility of Staphylocccus aureus isolates from quarter milk samples from large- $(\mathrm{n}=201)$ and small-scale $(\mathrm{n}=201)$ farms. Number (\%) of isolates with different susceptibilities (resistant, intermediate, and susceptible).

\begin{tabular}{|c|c|c|c|c|c|c|c|}
\hline $\begin{array}{l}\text { Antimicrobial } \\
\text { drug }(\mu \mathrm{g})\end{array}$ & \multicolumn{3}{|c|}{ Large-scale farms } & \multicolumn{3}{|c|}{ Small-scale farms } & $P$-value \\
\hline Penicillin G (30) & $33(16.4)$ & $5(2.5)$ & $163(81.1)$ & $62(30.8)$ & $6(3.0)$ & $133(66.2)$ & 0.001 \\
\hline Chloramphenicol (10) & $11(5.5)$ & $26(12.9)$ & $164(81.6)$ & $16(8.0)$ & $8(4.0)$ & $177(88.0)$ & 0.071 \\
\hline Erythromycin (15) & $18(8.9)$ & $29(14.4)$ & $154(76.7)$ & 39 (19.4) & $23(11.4)$ & $139(69.2)$ & 0.092 \\
\hline Trimethoprim/sulfamethazine $(23.8 / 1.2)$ & $5(2.5)$ & $4(2.0)$ & $192(95.5)$ & $6(3.0)$ & $1(0.5)$ & $194(96.5)$ & 0.610 \\
\hline
\end{tabular}

${ }^{1}$ The $P$-value refers to differences between large and small farms in the prevalence of isolates resistant to the respective antimicrobial drug, as evaluated by the $t$-test.

conceptual frameworks. The producers $(n=242)$ were questioned about their usage of antimicrobial drugs and their attitudes toward education in related subjects. Indices used as prompts were: preventive management, existing residue control tests, preparation of antimicrobial drugs, public health concerns, disposal of surplus antimicrobial drugs, and persistence of antimicrobial drug residues in milk. The availability of records documenting treatments (treatment date, animal identification, type of antibiotic, dose, withholding period) on the farms was also established in the interviews.

\section{RESULTS AND DISCUSSION}

Staphylococcus aureus is regarded as an important mastitis pathogen in the bovine in Kenya and is the most frequent pathogen isolated from mastitic milk (Odongo and Ambani, 1989). In this study, the prevalence of Staph. aureus in milk from the sampled cows was found to be $30.6 \%$, which was lower than in the studies by Ngatia (1988), who observed a prevalence of $55 \%$. The previous study was, however, concentrated around a single area, and the findings from the current study represent a wider geographic region.

The quality control organisms yielded values within the established ranges, indicating that the test was performed in a satisfactory manner. Comparing isolates from small and large farms, there was a difference in the overall mean prevalence of resistance of $7.6 \%$. The difference in overall mean susceptibility was $4.7 \%$ between isolates from the 2 farm categories. The difference in overall distribution of the susceptibility patterns was compared using the $\chi^{2}$ test and found to be significant $(P<0.05)$. For this comparison, resistant and intermediate isolates were combined. There was a significant difference $(P<0.05)$ between isolates from the producer categories in their susceptibility to penicillin $\mathrm{G}$ and tetracycline (Table 1). This likely indicates differences in the usage pattern of the 2 antibiotics between large- and small-scale producers and a selection pressure for these antibiotics on small farms. In an earlier study (Shitandi and Sternesjö, 2001), penicillin was the most commonly found type of antibiotic residue in milk, with levels often exceeding the maximum residue limit for penicillin $G$ in milk established in the European Union $(4 \mu \mathrm{g} / \mathrm{kg})$ by 2 -fold. Because there was little information regarding the actual use of drugs and treatment regimens on the different farms, a relationship between antimicrobial usage and resistance could not be conclusively established in this study.

In Kenya, there is no formal system for surveillance of antibiotic resistance in animal bacterial isolates, a common trend in many low-income countries (Hart and Kariuki, 1998). Among the 402 isolates from the 2 types of farms, multiple resistance, defined as lack of susceptibility to at least 2 antibiotics from different families, was observed in $69(34.3 \%)$ of the isolates from the small-scale farms compared with 36 (17.9\%) of the isolates from the large-scale farms (Table 2). The difference in overall prevalence of multidrug resistant Staph. aureus isolates between the 2 producer categories was significant as determined by the $\chi^{2}$ test $(P<0.05)$, combining resistant and intermediate isolates in the comparison.

Staphylococcus aureus has developed multidrug resistance in many regions of the world (World Health Organization, 2000), although reported prevalence rates indicate that wide variations exist regionally and even from herd to herd (Waage et al., 2002). Penicillin often predicts susceptibility to other $\beta$-lactamase-sensitive antimicrobial agents, for example, ampicillin, and this has been used in several studies of Staph. aureus resistance. In an Argentinian study, penicillin resistance was reported to be $30 \%$ (Gentilini et al., 2000). In Finland, more than $50 \%$ of the Staph. aureus isolates are penicillin-resistant (Pitkälä et al., 2004), which is significantly higher than data reported from other Nordic countries, for example, $30 \%$ in Denmark (DANMAP, 2002 ), $5 \%$ in Norway (NORM/NORM-VET, 2000), and 7\% (Staph. aureus isolated from acute clinical mastitis) in Sweden (SVARM, 2003). The high penicillin resistance amongst Staph. aureus in Finland is likely due to 
Table 2. Susceptible and multiple-resistant Staphylococcus aureus isolates in quarter milk samples from small and large dairy herds $(\mathrm{n}=$ 402). Percentage of isolates within each category is shown in parentheses. Resistant and intermediate isolates were combined in one category for $\chi$-square testing of differences in the overall distribution of multidrug resistant $S$. aureus between large- and small-scale farms.

\begin{tabular}{llllllll}
\hline Farm category & $\begin{array}{l}\text { Isolates } \\
\text { (n) }\end{array}$ & $\begin{array}{l}\text { Susceptible to } \\
\text { all 5 antibiotics }\end{array}$ & $\begin{array}{l}\text { Susceptible to 4 } \\
\text { of 5 antibiotics }\end{array}$ & $\begin{array}{l}\text { Susceptible to } 3 \\
\text { of } 5 \text { antibiotics }\end{array}$ & $\begin{array}{l}\text { Susceptible to 2 } \\
\text { of } 5 \text { antibiotics }\end{array}$ & $\begin{array}{l}\text { Susceptible to } 1 \\
\text { of } 5 \text { antibiotics }\end{array}$ & $\begin{array}{l}\text { Susceptible to 0 } \\
\text { of } 5 \text { antibiotics }\end{array}$ \\
\hline Large & 201 & $132(65.7)$ & $33(16.4)$ & $10(5.0)$ & $16(8.0)$ & $9(4.5)$ & $1(0.5)$ \\
Small & 201 & $122(60.6)$ & $10(5.0)$ & $37(18.4)$ & $27(13.4)$ & $4(2.0)$ & $1(0.5)$ \\
\hline
\end{tabular}

the wide use of intramammary preparations containing combinations and broad-spectrum antibiotics (Pitkälä et al., 2004), in contrast to the stringent policies in place for usage of antimicrobial drugs in countries such as Sweden.

The overall proportion of farmers with a documented use of antimicrobial drugs was $41.3 \%$. Treatment records and protocols were more likely to be absent among small-scale producers (78\%) than among large-scale producers $(27 \%)$; odds ratio $=9.5,95 \%$ confidence inter$\mathrm{val}=5.2$ to 17.3 . The difference in the overall distribution of the availability of treatment records between the 2 producer categories was significant $(P<0.05)$. The lack of documentation amongst small-scale producers, however, should be taken cautiously, as this in itself does not indicate nonusage. There could be other risk factors such as inappropriate dose or combination of drugs, even when documentation is present.

The study was also interested in identifying underlying reasons and farmer needs which might contribute to the antimicrobial resistance problems. From the results, $34 \%$ of the farmers ranked information on the use of preventive management to minimize reliance on antibiotics and treatment programs highest of the indices (Table 3). They also expressed a need for a simple, sensitive, and inexpensive test to control residues, and for information on the correct handling of antimicrobial drugs on farm. From the additional remarks made, respondents were able to detect the clinical form of mastitis. Subclinical cases might, however, go undetected due to lack of knowledge and necessary diagnostic facilities, in agreement with the situation in Ethiopia (Hussein et al., 1997). Efforts by the farmer were seemingly focused on treatment of clinical cases rather than on preventative measures. Most dairy farmers may thus not be aware of the existence of the subclinical form or the importance of resistant strains and their potential transfer from animals to humans (Witte, 1998). The risk that consumers are directly exposed to drug-resistant bacteria is, however, minimized by the fact that milk is seldom consumed without first being boiled. In Kenya, milk is traditionally not consumed as drinking milk but is more commonly used for preparation of a meal, e.g., porridge.

\section{CONCLUSIONS}

This study suggests herd size is an indirect risk factor in the development of antibiotic resistance in Staph. aureus, as evident from the observed differences in antimicrobial susceptibility and prevalence of drug resistant Staph. aureus in milk between producer categories in Kenya. Due to lack of documentation regarding treatment regimens and difficulties in establishing the types of antimicrobial drugs the small-scale farmers actually used, the relationship between the use of drugs and resistance development could not be investigated.

\section{ACKNOWLEDGMENTS}

This work was supported by the Swedish Institute (SI) and a research fellowship award, by the Jawaharlal Nehru Centre for Advanced Scientific Research (JNCASR) and Committee on Science and Technology in Developing Countries of the International Council for Science (COSTED-ICSU). We are grateful to the various milk producers who participated in the study. We thank N. Ojango of Delamere estates (Kenya), C.

Table 3. Aspects related to the use of antimicrobial drugs, where farmers expressed a need for information, and how these were ranked when farmers were asked to identify the aspect that should be given highest priority $(\mathrm{n}=234)$.

\begin{tabular}{ll}
\hline $\begin{array}{l}\text { Areas where a need } \\
\text { for information exists }\end{array}$ & $\begin{array}{l}\text { Farmers ranking } \\
\text { highest priority }(\%)\end{array}$ \\
\hline Use of preventive management to minimize reliance on antibiotic drugs & 34.0 \\
Simple, sensitive, and inexpensive tests to control residues in milk & 22.8 \\
Preparation of antibiotics for use on farm & 20.0 \\
Public health aspects related to antibiotic residues in milk & 11.2 \\
Disposal of surplus farm antibiotics & 7.8 \\
Likelihood of residues persisting in milk from the different antimicrobial drugs available \\
\hline
\end{tabular}


Concha (National Veterinary Institute, Uppsala, Sweden), and E. Olden and C. Ericksson (students at the Swedish University of Agricultural Sciences, Uppsala) for assistance at various stages in the field investigations.

\section{REFERENCES}

Arbeit, D. 1988. Laboratory procedures for the epidemiological analysis of Staphylococci. Pages 203-286 in Staphylococci and Staphylococci Diseases. G. Archer and T. Crossley, ed. Churchill Livingstone, New York, NY.

DANMAP. 2002. Use of antimicrobial agents and occurrence of antimicrobial resistance in bacteria from food animals, foods and humans in Denmark. 2003. Danish Veterinary Institute, Copenhagen, Denmark.

Gentilini, E., G. Denamiel, P. Llorente, S. Godaly, M. Rebuelto, and O. Degregorio. 2000. Antimicrobial susceptibility of Staphylococcus aureus isolated from bovine mastitis in Argentina. J. Dairy Sci. 83:1224-1227.

Hart, A., and S. Kariuki. 1998. Antimicrobial resistance in developing countries. Br. Med. J. 317:647-650.

Hussein, A., N. Y. Teshome, and G. Tilahun. 1997. Prevalence of mastitis in different local and exotic breeds of milking cows. Ethiop. J. Agric. Sci. 16:53-60.

International Dairy Federation. 1985. Standard 50B. Milk and milk products. International Dairy Federation, Brussels, Belgium.

Klastrup, O., and P. Schmidt. 1974. Nordic recommendations concerning mastitis control of quarter samples. Nordic Vet. Med. 26:197-204.

Mitema, E., G. Kikuvi, H. Wegener, and K. Stohr. 2001. An assessment of antimicrobial consumption in food processing animals in Kenya. Vet. Pharmacol. Ther. 24:385-390.

National Committe for Clinical Laboratory Standards. 2002. Performance standards for antimicrobial susceptibility testing. 12th Informational Supplement, NCCLS M100-S12, Vol. 21, No 1. NCCLS, Pennsylvania, PA.

National Mastitis Council. 1992. Laboratory Handbook on Bovine Mastitis. National Mastitis Council, Inc., Madison, WI.
Ngatia, T. A. 1988. Aetiology and pathology of subclinical mastitis in dairy cows. Ph.D. Diss., Univ. Nairobi, Kenya.

NORM/NORM-VET. 2000. Consumption of antimicrobial agents and occurrence of antimicrobial resistance in Norway. 2001. ISSN: $1507-2307$.

Odongo, O., and A. Ambani. 1989. Microorganisms isolated from bovine milk samples submitted to veterinary diagnostic laboratory, Kabete, Kenya. Bull. Anim. Health Prod. Afr. 37:195-196.

Omore, A., H. Muriuki, M. Kinyanjui, M. Owango, and S. Staals. 1999. The Kenyan dairy sector: A rapid appraisal. Research report of the MOA/KARI/ILRI smallholder dairy project. International Livestock Research Institute, Nairobi, Kenya.

Pitkälä, A., M. Haveri, S. Pyörälä, V. Myllys, and T. HonkanenBuzalski. 2004. Bovine masitits in Finland 2001-prevalence, distribution of bacteria, and antimicrobial resistance. J. Dairy Sci. 87:2433-2441.

Schalm, O., and O. Noorlander. 1957. Experiments and observations leading to development of California mastitis test. JAVMA 130:199-204.

Shitandi, A., and Å. Sternesjö. 2001. Detection of Antimicrobial drug residues in Kenyan milk. J. Food Safety 21:205-214.

Shitandi, A., and A. Sternesjö. 2003. Factors contributing to the occurrence of antimicrobial drug residues in Kenyan milk. J. Food Prot. 67:399-402.

SVARM (Swedish Veterinary Antimicrobial Resistance Monitoring). 2003. National Veterinary Institute, Uppsala, Sweden.

Veldhuizen, L., A. Waters-Bayer, and D. Zeeuw. 1997. Developing Technology with Farmers: A Trainer's Guide for Participatory Learning. Zed Books, London, UK.

Waage, S., J. Bjorland, A. Caugant, H. Oppegaard, T. Tollersrud, T. Mørk, and F. Aarestrup. 2002. Spread of Staphylococcus aureus resistant to penicillin and tetracycline within and between dairy herds. Epidemiol. Infect. 129:193-202.

Wiedemann, B. 1993. Monitoring of resistant organisms in man and identification of their origin. Vet. Microbiol. 35:275-284.

Witte, W. 1998. Medical consequences of antibiotic use in agriculture. Science 279:996-997.

World Health Organization. 2000. Overcoming antimicrobial resistance. Page 67 in Report on Infectious Diseases. Geneva, Switzerland. 